\title{
Faktor - faktor yang Berhubungan dengan Mutu Pelayanan terhadap Kepuasan Pasien
}

\author{
Mukhlisiana Ahmad \\ Akademi Kebidanan Bogor Husada, J. H. Soleh Iskandar No.4, \\ Kedung Badak, Tanah Sereal, Kedung Badak, Tanah Sereal, Kota Bogor, \\ Jawa Barat 16164, Tlp:(0251) 8333399
}

\begin{abstract}
Abstrak
Salah satu indikator keberhasilan pelayanan kesehatan adalah kepuasan pasien. Kepuasan didefinisikan sebagai penilaian pasca konsumsi, bahwa suatu produk yang dipilih dapat memenuhi atau melebihi harapan pasien, sehingga mempengaruhi proses pengambilan keputusan untuk pembelian ulang produk yang sama. Pengertian produk mencakup barang, jasa, atau campuran antara barang dan jasa. Produk rumah sakit adalah jasa pelayanan kesehatan. Secara umum penelitian ini bertujuan untuk mengetahui Faktor-faktor yang Berhubungan dengan Mutu Pelayanan terhadap Kepuasan Pasien di Rumah Sakit Graha Permata Ibu Tahun 2016. Penelitian ini bersifat Cross Sectional, untuk menentukan sampel penelitian ini menggunakan tehnik Accidental Sampling yaitu dengan cara memilih pasien rawat jalan yang kebetulan ada dijumpai di RS Graha Permata lbu dengan sampel yang digunakan 55 orang pasien di RS Graha Permata Ibu. Dari hasil penelitian ini di dapatkan hasil tidak ada hubungan antara Tangibles terhadap kepuasan pasien, dan tidak ada hubungan antara Reabillity terhadap kepuasan pasien, dan pada aspek Responsiveness tidak ada hubungan antara Responsiveness terhadap kepuasan pasien, dan juga tidak ada hubungan antara Assurance terhadap kepuasan pasien, sedangkan pada aspek Empathy dinyatakan ada hubungan antara Empathy terhadap kepuasan pasien di RS Graha Permata Ibu dengan P-Value $=0.008$, dengan $\alpha=0.05$. Pada hasil penelitian di RS Graha Permata Ibu hasil yang peneliti dapat memang tidak semua aspek berhubungan, hanya aspek Empathy yang berhubungan dengan kepuasan pasien, namun aspek-aspek di atas harus selalu diperhatikan dan selalu di utamakan terutama aspek Empathy yang berpengaruh dimana petugas harus lebih maksimal memberikan perhatian dan rasa peduli kepada pasien yang berkunjung ke RS Graha Permata Ibu.
\end{abstract}

Kata kunci : Mutu Pelayanan, Kepuasan Pasien

\section{Abstract}

One indicator of the success of health care is patient satisfaction. Satisfaction is defined as the post-consumption assessment, that a product is selected to meet or exceed the expectations of patients, thus affecting the decision to purchase the same product again. Definition of products includes goods, services, or a mixture of goods and services. Product hospitals are health care services. Generally, this study aims to determine the Factors Associated with Quality of Service to Patient Satisfaction in Grata Permata Ibu Hospital in 2016. This study is a cross sectional study to determine the sample using accidental sampling technique that is by selecting outpatients who happened to be found in Graha Permata lbu Hospital sample 55 patients in Graha Permata lbu Hospital, From the results of this study in get results no relationship between Tangibles to patient satisfaction, and there is no relationship between Reabillity to patient satisfaction, and in no aspect Responsiveness Responsiveness of the relationship between patient satisfaction, and also there is no relationship between patient satisfaction Assurance, while the aspect Empathy Empathy stated there is a relationship between patient satisfaction in Graha Permata lbu Hospital with P-Value $=0.008$, with $\alpha=0.05$ level. On the results of research in Graha Permata lbu Hospital outcomes researchers can indeed not all related aspects, only Empathy aspects related to patient satisfaction, but above aspects should be kept in mind and always in priority Empathy particularly influential as pect in which the officer must be a maximum attention and a sense of care for patients who visit the Graha Permata lbu Hospital.

Keywords : Quality of Care, Patient Satisfaction 


\section{Pendahuluan}

Kepuasan akan dirasakan pasien saat pelayanan kesehatan yang diterima sesuai terhadap yang di harapkan, tingkat kepuasan dipengaruhi oleh respon perawat, kecepatan pelayanan, keramahan dan kejelasan informasi yang dilakukan oleh perawat. Kompla in terhadap pelayanan kesehatan merupakan pemicu untuk melakukan pembaharuan menuju perbaikan, selain itu adanya kompla in juga dapat dijadikan sebagai suatu kesempatan untuk menunjukan pelayanan yang lebih baik pada pelanggan. ${ }^{1}$

Kepuasan adalah tingkat keadaan yang dapat dirasakan seseorang yang merupakan hasil dari membandingkan penampilan atau outcome produk yang dirasakan dalam hubungannya dengan harapan seseorang. ${ }^{2}$

kepuasan dikonseptualisasikan sebagai perasaan yang timbul setelah mengevaluasi pelayanan keperawatan pasien. Suatu respon emosional terhadap pengalaman berkaitan dengan pelayanan yang dirasakan selama di rawat di rumah sakit. Respon emosional dipicu proses evaluatif dimana persepsi (atau keyakinan) terhadap sebuah objek, tindakan, atau kondisi dibandingkan dengan nilai-nilai (atau kebutuhan, keinginan, hasrat,) seseorang. ${ }^{3}$

Syarat pelayanan kesehatan yang baik setidaknya dapat dibedakan atas 13 macam, yakni tersedia (available), menyeluruh (comprehensive), terpadu (integrated), berkesinambungan (continue), adil merata (equity), mandiri (suitainable), wajar (appropriate), dapat diterima (acceptable), dapat dicapai (accessible), dapat dijangkau (affordable), efektif (effective), efisien (efficient), serta bermutu (quality).

Disinilah tampak syarat mutu makin bertambah penting. Mudah dipahami karena apabila pelayanan kesehatan yang bermutu dapat diselenggarakan, bukan saja akan dapat menghindari terjadinya berbagai efek samping (side efect) karena pengukuran kemajuan ilmu dan teknologi kesehatan, tetapi sekaligus juga akan dapat memenuhi kebutuhan dan tuntutan kesehatan masyarakat (health needs and demands) yang semakin meningkat. Suatu penelitian yang dilakukan oleh Smith dan Metzner menunjukkan dimensi mutu pelayanan kesehatan yang dipandang paling penting ada lah efis ien pelayanan kesehatan (45\%), kemudian baru menyusul perhatian dokter secara pribadi kepada pasien (40\%), pengetahuan ilmiah yang dimiliki dokter (40\%), keterampilan yang dimiliki dokter (35\%), serta kenyamanan pelayanan kesehatan yang dirasakan oleh pasien (35\%). Dalam membicarakan mutu pelayanan kesehatan, seyogyanya pedoman yang dipakai adalah hakekat dasar dari diselenggarakannya pelayanan kesehatan tersebut. Maksud dari hakekat dasar disini tidak lain adalah untuk memenuhi kebutuhan dan tuntutan kesehatan (health needs and demands) dari para pemakai jasa pelayanan kesehatan yang apabila berhasil dipenuhi akan dapat menimbulkan rasa puas (client satisfaction) terhadap pelayanan kesehatan yang diselenggarakan. ${ }^{4}$

Masih tingginya jumlah pasien Indonesia yang berobat baik ke Singapura maupun Malaysia merupakan fenomena yang memprihatinkan. Hal ini menjadi salah satu bukti bahwa rumah sakit di Indonesia belum sepenuhnya dapat memberikan layanan terbaik kepada pasien. Menurut National Healthcare Group International Research Development Singapore, 50 persen pasien internasional yang berobat di Singapura adalah warga Indonesia. Sedangkan rata-rata jumlah pasien Indonesia yang berobat ke Malays ia adalah 12 ribu orang per tahun. Banyaknya kunjungan orang Indonesia yang berobat ke luar negeri tentu memprihantinkan. Mengapa kita tidak bisa memberikan layanan medis yang lebih baik untuk rakyat kita. Masalah mutu serta kepuasan dalam pelayanan, diakui Menkes Nafsiah masih menjadi tantangan terbesar bagi rumah sakit di Indonesia. Rumah sakit di Tanah Air sudah seharusnya meningkatkan kualitas pelayanan serta mengikuti tuntutan dan kebutuhan yang berkembang masyarakat agar pasien yang berobat ke luar negeri mau kembali berobat di negeri sendiri. "Peningkatan mutu dan kualitas rumah sakit harus sesuai dengan perkembangan tuntutan dan kebutuhan. Diakui Nafsiah, tantangan bagi Industri rumah sakit di Tanah Air makin berat menyusul telah diberlakukannya pasar bebas di tingkat ASEAN, dan pasar bebas tingkat Asia Pasifik pada 2020 mendatang. Selain banyaknya pasien yang senang berobat ke luar negeri, tantangan lainnya adalah belum kompetitifnya asuransi dan penyedia layanan dalam memberikan layanan kesehatan serta mutu pelayanan rumah sakit yang belum dianggap berstandar Internasional. $^{5}$

Hasil penelitian Mulyana Haq, dalam penelitian yang berjudul Pengaruh Pemaparan Hasil Survey Terhadap Peningkatan Kepuasan Pasien Di Poli Kia Puskesmas Kecamatan Cilandak, Jakarta Selatan, Tahun 2002 diperoleh hasil sebesar 27,5\% pasien menyatakan tidak puas terhadap pelayanan poli KIA. ${ }^{6}$

Selain itu Hasil penelitian Soraya dalam penelitian yang berjudul Kepuasan Pasien Rawat Inap Terhadap Pelayanan Keperawatan Di Paviliun Khusus Ibnu Sina Rumah Sakit Islam Khadijah Palembang Tahun 2005 menunjukkan 
bahwa pasien yang puas hanya 49\% (kepuasan pada dimensi tengibles 53\%, dimensi reliability $52 \%$, dimensi responsiveness 49\%, dimensi assurance 50\% dan dimensi emphaty 53\%). ${ }^{7}$

Dari hasil penelitian diatas menunjukkan bahwa kepuasan pasien merupakan salah satu indikator mutu pelayanan kesehatan. Salah satu cara untuk mengukur sikap pelanggan ialah menggunakan kuesioner, yaitu kuesioner kepuasan pelanggan. ${ }^{8}$

Pada bulan Juni-Desember Tahun 2016 di RS graha Permata Ibu terdapat laporan complain sebanyak 191 orang, yang menyatakan complain, dan menurut data kunjungan pasien di RS Graha Permata Ibu, selalu ada peningkatan setiap tahun nya, tetapi belum sesuai dengan target/pencapaian Indikator RS Graha Permata Ibu: BOR (Bed Occupancy Rate): 60-80\% (persen). ALOS (Average Lenght of Stay): 6-9 hari. TOI (Turn Over Internal): 1-3 hari. BTO (Bed Turn Over): 40-50 kali. ${ }^{9}$

Disini peneliti tertarik untuk meneliti apakah pasien di RS Graha Permata Ibu merasa Puas/Tidak puas dengan pelayanan yang telah diberikan oleh petugas pelayanan kesehatan. Untuk meneliti Faktor-Faktor yang berhubungan dengan Mutu Pelayanan terhadap Kepuasan Pasien di Rumah Sakit Graha Permata Ibu. Peneliti merasa perlu membantu rumah sakit dalam usaha mempertahankan dan meningkatkan kualitas pelayanan rumah sakit dan mempertahankan mutu pelayanan, sehingga menjadi pelayanan kesehatan yang terpercaya.

\section{Kerangka Konsep \\ Independent}

\section{Dependent}

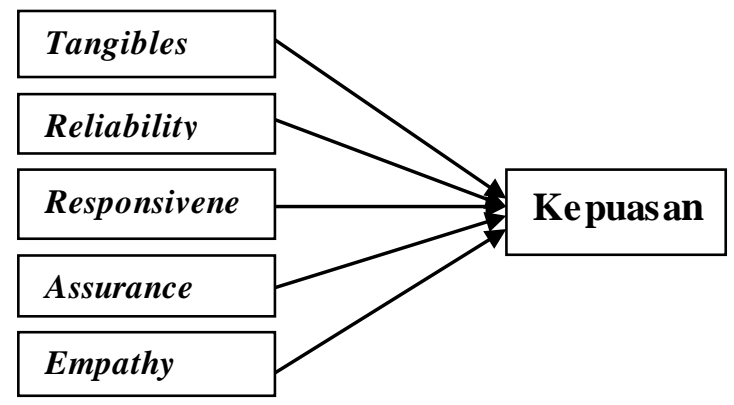

Secara umum penelitian ini bertujuan untuk mengetahui Faktor-faktor yang Berhubungan dengan Mutu Pelayanan terhadap Kepuasan Pasien di Rumah Sakit Graha Permata Ibu Tahun 2013.

\section{Metode}

Penelitian ini bersifat Cross Sectional. Dimana penelitian ini hanya dilakukan pada satu waktu saja. Data yang dikumpulkan dengan cara, membagikan kuesioner mengenai kepuasan pasien terhadap pelayanan kesehatan di Rumah Sakit. Penelitian dilaksanakan di RS Graha Permata Ibu yang beralamatkan Jl. KH. M. Usman (Raya Kukusan) No. 168. Depok pada Bulan Maret-Juni 2013. Populasi yang ada pada penelitian ini adalah semua pasien rawat jalan yang berkunjung ke RS Graha Permata Ibu, Juni 2013. Untuk menentukan jumlah sampel peneliti menggunakan teknik Accidental Sampling yaitu metode pengambilan sampel dengan cara memilih pasien rawat jalan yang kebetulan ada di jumpai di Rumah Sakit dengan target sampel 55 responden di RS Graha Permata Ibu, pada tanggal 27-28 Tahun 2013.

\section{Hasil}

\section{Analisa Bivariat}

Pada analisis dilakukan secara komputerisasi dan ini digunakan program analisis data yaitu SPSS versi 18.0 yang terbagi menjadi data yang berkategorik. Dari hasil analisa bivariat tersebut diringkas dalam bentuk tabel sebagai berikut :

Tabel 1. Hubungan Tangibles (Berwujud) terhadap Kepuasan Pasien

\begin{tabular}{lcccc}
\hline \multirow{3}{*}{ Tangibles } & \multicolumn{3}{c}{ PelayananKesehatan } & \\
\cline { 2 - 4 } & TidakPuas & Puas & Total & Pv \\
\cline { 2 - 4 } & $\mathrm{n}$ & $\mathrm{n}$ & $\mathrm{n}$ & \\
\hline KurangBaik & 14 & 9 & 23 & \\
Baik & 17 & 15 & 35 & 0,767 \\
Total & 31 & 24 & 55 & \\
\hline
\end{tabular}

Berdasarkan Hasil Analisa Bivariat (Tabel 1.) antara Tangibles (Berwujud) dengan Kepuasan Pasien terhadap pelayanan kesehatan di peroleh hasil bahwa kepuasan pasien terhadap pelayanan kesehatan yang menyatakan Tangibles kurang baik sebanyak 14 orang dan merasa tidak puas, sedangakan yang menyatakan tangibles baik tetapi menyatakan tidak puas 17 orang, kepuasan pasien terhadap pelayanan kesehatan yang menyatakan tangibles kurang baik namun merasa puas sebanyak 9 orang, sedangkan kepuasan pasien terhadap pelayanan kesehatan yang menyatakan tangibles baik dan merasa puas sebanyak 15 orang.

Setelah diuji secara statistic dengan uji ChiSquare, diperoleh $p$-value $=0.767$, dengan $\alpha=$ 0.05 yang artinya tidak ada hubungan antara Tangibles dengan kepuasan pasien terhadap pelayanan kesehatan di RS GPI tahun 2013.

Berdasarkan hasil analisa bivariat (Tabel 2) antara Reability (keandalan) dengan Kepuasan Pasien terhadap pelayanan kesehatan di peroleh hasil bahwa kepuasan pasien terhadap pelayanan kesehatan yang menyatakan Reliability tidak andal sebanyak 5 orang dan merasa tidak puas, sedangkan yang menyatakan Reliability andal 
tetapi menyatakan tidak puas 26 orang, kepuasan pasien terhadap pelayanan kesehatan yang menyatakan Reliability tidak andal namun merasa puas sebanyak 6 orang, sedangkan kepuasan pasien terhadap pelayanan kesehatan yang menyatakan Reliability andal dan merasa puas sebanyak 18 orang.

Tabel 2. Hubung an Reliabillity (Andal) Terhadap Kepuas an Pasien

\begin{tabular}{|c|c|c|c|c|}
\hline \multirow{3}{*}{ Reliabillity } & \multicolumn{3}{|c|}{ Pelayanan Kesehatan } & \multirow{3}{*}{$\mathrm{Pv}$} \\
\hline & Tidak Puas & Puas & Total & \\
\hline & $\mathbf{n}$ & $\mathbf{n}$ & $\mathbf{n}$ & \\
\hline Tidak Andal & 5 & 6 & 11 & \multirow{3}{*}{0,634} \\
\hline Andal & 26 & 18 & 44 & \\
\hline Total & 31 & 24 & 55 & \\
\hline
\end{tabular}

Setelah diuji secara statistic dengan uji ChiSquare, diperoleh $p$-value $=0.634$, dengan $\alpha=$ 0.05 yang artinya tidak ada hubungan antara Reliability dengan kepuasan pasien terhadap pelayanan kesehatan di RS GPI tahun 2013.

Tabel 3. Hubungan Responsiveness (Daya Tanggap) Terhadap Kepuasan Pasien

\begin{tabular}{ccccc}
\hline & \multicolumn{3}{c}{ Pelayanan Kesehatan } & \\
\cline { 2 - 4 } Responsiveness & Baik & $\begin{array}{l}\text { Tidak } \\
\text { Baik }\end{array}$ & Total & Pv \\
\cline { 2 - 3 } & $\mathbf{n}$ & $\mathbf{n}$ & $\mathbf{n}$ & \\
\hline Kurang & 5 & 2 & 7 & \\
Tanggap & & & & \\
Tanggap & 26 & 22 & 48 & 0,451 \\
Total & 31 & 24 & 55 & \\
\hline
\end{tabular}

Berdasarkan hasil analisa bivariat (Tabel 3.) antara Responsiveness dengan Kepuasan Pasien terhadap pelayanan kesehatan di peroleh hasil bahwa kepuasan pasien terhadap pelayanan kesehatan yang menyatakan Responsiveness kurang tanggap sebanyak 5 orang dan merasa tidak puas, sedangakan yang menyatakan Responsiveness tetapi menyatakan tidak puas 26 orang, kepuasan pasien terhadap pelayanan kesehatan yang menyatakan Responsiveness kurang tanggap namun merasa puas sebanyak 2 orang, sedangkan kepuasan pasien terhadap pelayanan kesehatan yang menyatakan Responsiveness tanggap dan merasa puas sebanyak 22 orang.

Setelah diuji secara statistic dengan uji ChiSquare, diperoleh $p$-value $=0.451$, dengan $\alpha=$ 0.05 yang artinya tidak ada hubungan antara Responsiveness dengan kepuasan pasien terhadap pelayanan kesehatan di RS GPI tahun 2013.

Tabel 4. Hubung an Assurance (Jaminan) Terhadap Kepuasan Pasien

\begin{tabular}{lcccc}
\hline \multirow{2}{*}{ Assurance } & \multicolumn{3}{c}{ Pelayanan } & \multicolumn{2}{c}{ Kesehatan } & \multirow{2}{*}{ Pv } \\
\cline { 2 - 4 } & Tidak Puas & Puas & Total & \\
\cline { 2 - 4 } & $\mathbf{n}$ & $\mathbf{n}$ & $\mathbf{n}$ & \\
\hline Kurang & 5 & 4 & 9 & \\
Pasti & & & & \\
Pasti & 26 & 20 & 46 & 1,000 \\
Total & 31 & 24 & 55 & \\
\hline
\end{tabular}

Berdasarkan hasil analisa bivariat (Tabel 4.) antara Assurance dengan Kepuasan Pasien terhadap pelayanan kesehatan di peroleh hasil bahwa kepuasan pasien terhadap pelayanan kesehatan yang menyatakan Assurance kurang pasti sebanyak 5 orang dan merasa tidak puas, sedangakan yang menyatakan Assurance pasti tetapi menyatakan tidak puas 26 orang, kepuasan pasien terhadap pelayanan kesehatan yang menyatakan Assurance kurang pasti namun merasa puas sebanyak 4 orang, sedangkan kepuasan pasien terhadap pelayanan kesehatan yang menyatakan Assurance pasti dan merasa puas sebanyak 20 orang.

Setelah diuji secara statistic dengan uji ChiSquare, diperoleh $p$-value $=0.767$, dengan $\alpha=$ 0.05 yang artinya tidak ada hubungan antara Assurance dengan kepuasan pasien terhadap pelayanan kesehatan di RS GPI tahun 2013.

Tabel 5. Hubungan E mpathy (Perhatian) Terhadap Kepuasan Pasien

\begin{tabular}{lcccc}
\hline \multirow{3}{*}{ Empathy } & \multicolumn{3}{c}{ Pelayanan Kesehatan } & \\
\cline { 2 - 4 } & $\begin{array}{l}\text { Tidak } \\
\text { Puas }\end{array}$ & Puas & Total & \multirow{2}{*}{ Pv } \\
\cline { 2 - 4 } & $\mathbf{n}$ & $\mathbf{n}$ & $\mathbf{n}$ & \\
\hline Kurang & 14 & 13 & 29 & \\
$\begin{array}{l}\text { Perhatian } \\
\text { Perhatian }\end{array}$ & 10 & 18 & 31 & 0,008 \\
Total & 24 & 31 & 55 & \\
\hline
\end{tabular}

Berdasarkan hasil analisa bivariat (Tabel 5.) antara Empathy dengan Kepuasan Pasien terhadap pelayanan kesehatan di peroleh hasil bahwa kepuasan pasien terhadap pelayanan kesehatan yang menyatakan Empathy kurang perhatian sebanyak 14 orang dan merasa tidak puas, sedangakan yang menyatakan Empathy perhatian tetapi menyatakan tidak puas 10 orang, kepuasan pasien terhadap pelayanan kesehatan yang menyatakan Empathy kurang perhatian namun merasa puas sebanyak 13 orang, sedangkan kepuasan pasien terhadap pelayanan kesehatan yang menyatakan Empathy perhatian dan merasa puas sebanyak 18 orang.

Setelah diuji secara statistic dengan uji ChiSquare, diperoleh $p$-value $=0.008$, dengan $\alpha=$ 0.05 yang artinya Ada hubungan antara Empathy 
dengan kepuasan pasien terhadap pelayanan kesehatan di RS GPI tahun 2013.

\section{Pembahasan}

\section{Hubungan Tangibles (berwujud) terhadap Kepuas an Pasien Pada Pelayanan Kesehatan}

Setelah diuji secara statistic dengan uji ChiSquare, diperoleh $p$-value $=0.767$, dengan $\alpha=$ 0.05 yang artinya tidak ada hubungan antara Tangibles dengan kepuasan pasien terhadap pelayanan kesehatan di RS Graha Permata Ibu Tahun 2013, namun Menurut Kotler dalam Buchari, A. Bahwa Tangibles (bukti langsung) pelayanan yaitu penampilan fasilitas fisik, peralatan dan berbagai materi komunikasi yang baik, menarik, terawat lancar yang berhubungan dengan tingkat kepuasan pelanggan. ${ }^{10}$ Teori Kotler sejalan dengan hasil penelitian Apriyani yang menyatakan ada hubungan antara persepsi bukti langsung pelayanan dengan kepuasan pasien. ${ }^{11}$

Walaupun temuan peneliti di atas yang menyebutkan bahwa tidak ada hubungan antara aspek tangibles dengan kepuasan pasien terhadap pelayanan kesehatan di RS, akan tetapi menurut hemat peneliti aspek ini perlu bahkan penting untuk diperhatikan dan tingkatkan, hal ini terjadi karena sesuatu yang tampak itu jauh lebih jelas terukur dibandingkan dengan sesuatu yang tidak tampak, diantaranya dapat terlihat dari penampilan fasilitas fisik seperti ruang tunggu, perwatan, ruang laboratorium dan lain-lain. Sehingga dengan demikian, maka asumsi peneliti menyebutkan bahwa tangibelitas penting, tetapi ada yang lebih diprioritaskan oleh pasien adalah bagaimana agar setelah mendapatkan pelayanan pasien sembuh dari penyakitnya sehingga selanjutnya berakibat (outcome) menjadi puas, dan berikutnya pasien akan kembali datang bila ia mengalami sakit kembali.

\section{Hubungan Reliabillity (Andal) terhadap Kepuas an Pasien Pada Pelayanan Kesehatan}

Setelah diuji secara statistic dengan uji ChiSquare, diperoleh $p$-value $=0.634$, dengan $\alpha=$ 0.05 yang artinya tidak ada hubungan antara Reliabillity dengan kepuasan pasien terhadap pelayanan kesehatan di RS Graha Permata Ibu Tahun 2013, namun Menurut Kotler dalam Buchari, A. Bahwa Reabillity (keandalan) yaitu kemampuan pelayanan untuk memberikan jasa sesuai dengan yang dijanjikan, terpercaya, akurat, dan konsisten dan hal tersebut berhubungan dengan tingkat kepuasan pelanggan. ${ }^{10}$ Teori Kotler tidak sejalan dengan Hasil penelitian Laila, bahwa tidak ada hubungan antara persepsi keandalan pelayanan dengan kepuasan pasien. $^{12}$

Menurut peneliti, sekalipun tidak ada hubungan antara Reabillity (kehandalan) dengan kepuasan pasien di rumah sakit, namun kemampuan pelayanan untuk memberikan jasa sesuai dengan yang dijanjikan, terpercaya, akurat, dan konsisten penting untuk dijadikan prioritas pelayanan, terutama karena ke depan pasien sudah jauh lebih pintar dalam memilih pelayanan yang baik untuknya. Sehingga jangan sampai ada kasus yang terjadi dibeberapa rumah sakit akhir-akhir ini misalnya pelayanan oprasi yang menyisakan benang pada hasil oprasi pada pasien, sehingga kasus ini mencedrai citra dari rumah sakit tersebut, tentu saja kejadian ini sangat tidak diinginkan.

\section{Hubungan Responsiveness (Daya Tanggap) terhadap Kepuasan Pasien Pada Pelayanan Kesehatan}

Setelah diuji secara statistic dengan uji ChiSquare, diperoleh $p$-value $=0.451$, dengan $\alpha=$ 0.05 yang artinya tidak ada hubungan antara Responsiveness dengan kepuasan pasien terhadap pelayanan kesehatan di RS Graha Permata Ibu Tahun 2013, namun menurut Kotler dalam Buchari, A. Bahwa Responsiveness (daya tanggap) yaitu kemauan dari petugas/keryawan dan dari pengusaha untuk membantu pelanggan dan memberikan jasa dengan cepat serta mendengar dan mengatasi keluhan dari konsumen dan hal tersebut berhubungan dengan tingkat kepuasan pelanggan. ${ }^{10}$ Teori Kotler tidak sejalan dengan hasil penelitian wieke, yang menyatakan tidak ada hubungan antara persepsi daya tanggap petugas dengan kepuasan pasien. ${ }^{13}$

Sekalipun tidak ada hubungan antara aspek responsiveness dengan kepuasan pasien terhadap pelayanan kesehatan di RS, namun demikian menurut peneliti hal ini tetap saja ketanggapan petugas terhadap pasien seperti memberikan jasa dengan cepat serta mendengar dan mengatasi keluhan dari konsumen adalah sesuatu yang menjadi fokus dan prioritas dalam pelayanan di rumah sakit. Lebih dari pada itu, bahwasanya setiap orang siapapun pasti ingin dilayani dengan cepat, sebagai contoh seseorang tidak ingin berlama-lama di di ruang tunggu karena sistem pelayanan yang lamban dan penuh prosedur yang berbelit-belit. Pada dasarnya, pasien dan keluarga pasien menginginkan adanya pelayanan yang penuh, sehingga setiap keluhan dapat segera direspon dengan baik dan cepat.

Hubungan Assurance (Jaminan) terhadap Kepuasan Pasien Pada Pelayanan Kesehatan 
Setelah diuji secara statistic dengan uji ChiSquare, diperoleh $p$-value $=0.767$, dengan $\alpha=$ 0.05 yang artinya tidak ada hubungan antara Assurance dengan kepuasan pasien terhadap pelayanan kesehatan di RS Graha Permata Ibu Tahun 2013, namun menurut Kotler dalam Buchari, A. Bahwa jaminanpelayanan yaitu kemampuan karyawan untuk menimbulkan keyakinan dan kepercayaanterhadap janji yang telah dikemukakan kepada konsumen, dan hal tersebut berhubungan dengan tingkat kepuasan pelanggan. ${ }^{10}$ Teori Kotler sejalan dengan penelitian Surya, ada hubungan antara persepsi jaminan pelayanan dengan kepuasan pasien. ${ }^{14}$

Melihat temuan tidak ada hubungan antara aspek Assurance dengan kepuasan pasien terhadap pelayanan kesehatan di RS, namun petugas harus tetap memperhatikan jaminan yang diberikan dan dijanjikan oleh RS untuk pasien yang berkunjung ke RS, bahwasanya semua pasien yang berkunjung di RS menginginkan jaminan yang terbaik dan meyakinkan sehingga pasien merasa puas dengan jaminan yang telah diberikan.

\section{Hubungan Empathy (Perhatian) terhadap Kepuas an Pasien Pada Pelayanan Kesehatan}

Setelah diuji secara statistic dengan uji ChiSquare, diperoleh $p$-value $=0.008$, dengan $\alpha=$ 0.05 yang artinya Ada hubungan antara Empathy dengan kepuasan pasien terhadap pelayanan kesehatan di RS Graha Permata Ibu Tahun 2013, namun menurut Kotler dalam Buchari, A. Bahwa Empathy (perhatian) yaitu kesediaan petugas/karyawan dan pengusaha untuk lebih peduli memberikan perhatian secara pribadi kepada pelanggan yang berhubungan dengan tingkat kepuasan pelanggan. ${ }^{10}$ Teori Kotler sejalan dengan penelitian Suyadi, yang menyebutkan ada hubungan antara persepsi perhatian petugas dengan kepuasan pasien. ${ }^{15}$

Pada aspek Empathy peneliti mendapati ada hubungan antara Tangibles terhadap kepuasan pasien, dikarenakan petugas kurang optimalnya menanamkan rasa Empathy, disini petugas harus lebih memperhatikan aspek Empathy dalam setiap pelayanan yang diberikan oleh petugas kepada pasien yang berkunjung, tanpa membeda-bedakan satu sama lain, aspek Empaty sangat penting dan berpengaruh terhadap pasien yang berkunjung ke $\mathrm{RS}$, manakala pasien yang datang ke Rs berbedabeda, banyak pasien yang berkunjung ingin dilayani dengan baik, jika pasien mendapati masalah pada penyakitnya pasti ingin diperhatikan dan dipedulikan dengan cepat oleh petugas kesehatan, jika pasien merasa diperhatikan dan dilayani dengan baik, sehingga mereka akan merasa puas.

\section{Kesimpulan}

Berdasarkan hasil analisis untuk tingkat Tangibles di dapatkan nilai $\mathrm{p}$ value sebesar = 0.767 , yang artinya tidak ada hubungan antara Tangibles dengan kepuasan pasien terhadap Pelayanan Kesehatan di Rumah Sakit Graha Permata Ibu Tahun 2013. Penelitian ini tidak sejalan dengan teori Kotler dan penelitian Apriyani. Berdasarkan hasil analisis untuk tingkat Reliabillity di dapatkan nilai $\mathrm{p}$ value sebesar = 0.634 , yang artinya tidak ada hubungan antara Reliabillity dengan kepuasan pasien terhadap Pelayanan Kesehatan di Rumah Sakit Graha Permata Ibu Tahun 2013. Berdasarkan hasil analisis untuk tingkat Responsiveness di dapatkan nilai $\mathrm{p}$ value sebesar $=0.451$, yang artinya tidak ada hubungan antara Responsiveness dengan kepuasan pasien terhadap Pelayanan Kesehatan di Rumah Sakit Graha Permata Ibu Tahun 2013. Berdasarkan hasil analisis untuk tingkat Assurance di dapatkan nilai $\mathrm{p}$ value sebesar $=$ 0.767, yang artinya tidak ada hubungan antara Assurance dengan kepuasan pasien terhadap Pelayanan Kesehatan di Rumah Sakit Graha Permata Ibu Tahun 2013. Berdasarkan hasil analisis untuk tingkat Empathy di dapatkan nilai p value sebesar $=0.008$, yang artinya ada hubungan antara Empathy dengan kepuasan pasien terhadap Pelayanan Kesehatan di Rumah Sakit Graha Permata Ibu Tahun 2013.

Pada hasil penelitian di RS Graha Permata Ibu hasil yang peneliti dapat memang tidak semua aspek berhubungan, hanya aspek Tangibles yang berhubungan dengan kepuasan pasien, namun aspek-aspek di atas harus selalu diperhatikan dan selalu di utamakan terutama aspek Tangibles yang berpengaruh dimana petugas harus lebih maksimal memberikan perhatian dan rasa peduli kepada pasien yang berkunjung ke RS, dimana lima aspek tersebut sangatlah penting dan berpengaruh terhadap pasien, jika petugas memberikan pelayanan dengan baik maka akan menghasilkan outcome yg baik pula.

\section{Saran}

Aspek Empathy sangatlah penting dan perlu ditingkatkan rasa Empathy (perhatian) atau peduli terhadap pasien tanpa membeda-bedakan pasien yang satu dengan yang lainnya, agar pasien merasa nyaman sehingga pasien merasa puas dengan pelayanan yang diberikan Rumah Sakit.

Perlu ditingkatanya rasa Empathy pada pasien dengan cara pendekatan terhadap pasien 
agar pasien tidak ragu atau segan untuk bertanya kepada petugas kesehatan, sehingga petugas akan tau apa yang dibutuhkan oleh pasien, sehingga petugas tau dan pasien terlayani dengan baik sehingga merasa puas dengan pelayanan yang diberikan oleh petugas kesehatan.

\section{Daftar Pustaka}

1. Wiraatmaja. Manajemen Pemasaran dan Pemasaran Jasa. Bandung: Alfabeta; 2009.

2. Purnomo AS, Faktor-Faktor yang Berhubungan dengan Kepuasan Pasien di Rumah Sakit. Gunung Jati; 2011.

3. Tjiptono F dan Gregorius C. Quality and Satisfaction. Yogyakarta: Ando Offset; 2005.

4. Saifudin. Parsitipasi Publik dalam Pembentukan Perundang-Undangan. Yogyakarta: FH UII Press; 2009.

5. Mboi N. http://www.google.commenkes.kompas.com , di unduh pada 11 Mei 2013.

6. Haq AM. http://www.sia.fkm-undip.ac.id, di unduh pada 11 Mei 2013.

7. Soraya B. http://digilib.litbang.depkes.ac.id, di unduh pada 11 Mei 2013.
8. Supranto J. Pengukuran Tingkat Kepuasan Pelanggan untuk Menaikkan Pangsa Pasar. Jakarta: Rineka Cipta; 2006.

9. Laporan Kegiatan Tahunan Rumah Sakit Graha Permata Ibu Tahun 2016.

10. Alma B. Manajemen Pemasaran dan Pemasaran Jasa. Bandung: , Alfabeta; 2005.

11. Apriyani. Analisis Kepuasan Pasien Terhadap Pelayanan Rawat Jalan Di Poliklinik Rumah Sakit Azra Tahun 2016.

12. Laila K. Faktor-faktor yang mempengaruhi kepuasan pasien rawat jalan rspad gatot soebroto jakarta Tahun 2016.

13. Wieke. Kepuasan Pasien Rawat Jalan Terhadap Pelayanan Perawat di Rumah Sakit Haji Jakarta Tahun 2010.

14. Surya. Tingkat Kepuasan Pasien Rawat Jalan Terhadap Ketepatan Waktu Pelayanan Oleh Tenaga Kesehatan Di RSUP Fatmawati Jakarta Tahun 2016.

15. Suyadi. Tingkat Kepuasan Pasien Terhadap Pelayanan Kesehatan di Unit Rawat Inap Di Rumah Sakit Zahirah Jakarta Tahun 2016. 